\title{
A FORTRAN IV COMPUTER PROGRAM FOR CALCULATING INTERPLANAR SPACINGS
}

A. L. Coffey, Jr.

\section{UNION CAREIDE CORPORATION}

\section{NUCLEAR DIVISION \\ OAK RIDGE Y-12 PLANT}

operated for the ATOMIC ENERGY COMMISSION under U. S. GOVERNMENT Contract W-7405 eng 26

UNION CARBIDE
OAK RIDGE Y-12 PLANT

P. O. BOX $Y$

OAK RIDGE, TENNESSEE 37830 


\section{DISCLAIMER}

This report was prepared as an account of work sponsored by an agency of the United States Government. Neither the United States Government nor any agency Thereof, nor any of their employees, makes any warranty, express or implied, or assumes any legal liability or responsibility for the accuracy, completeness, or usefulness of any information, apparatus, product, or process disclosed, or represents that its use would not infringe privately owned rights. Reference herein to any specific commercial product, process, or service by trade name, trademark, manufacturer, or otherwise does not necessarily constitute or imply its endorsement, recommendation, or favoring by the United States Government or any agency thereof. The views and opinions of authors expressed herein do not necessarily state or reflect those of the United States Government or any agency thereof. 


\section{DISCLAIMER}

Portions of this document may be illegible in electronic image products. Images are produced from the best available original document. 
Printed in the United States of America. Available from Clearinghouse for Federal

Scientific and Technical Information, National Bureau of Standards,

U.S. Department of Commerce, Springfield, Virginia 22151

Price: Printed Copy $\$ 3.00$; Microfiche $\$ 0.65$

\section{LEGAL NOTICE}

This report was prepared as an account of Government sponsored work. Neither the United States, nor the Commission, nor any person acting on behalf of the Commission:

A. Makes any warranty or representation, expressed or implied, with respect to the accuracy, completeness, or usefulness of the information contained in this report, or that the use of any information, apparatus, method, or process disclosed in this report may not infringe privately owned rights; or

B. Assumes any liabilities with respect to the use of, or for damages resulting from the use of any information, apparatus, method, or process disclosed in this report.

As used in the above, "person acting on behalf of the Commission" includes any employee or contractor of the Commission, or employee of such contractor, to the extent that such employee or contractor of the Commission, or employee of such contractor prepares, disseminates, or provides access to, any information pursuant to his employment or contract with the Commission, or his employment with such contractor. 
Date Issued: July 15, 1970

\title{
UNION CARBIDE CORPORATION Nuclear Division
}

\author{
OAK RIDGE $Y-12$ PLANT
}

Operated under Contract W-7405-eng-26

With the US Atomic Energy Commission

\section{A FORTRAN IV COMPUTER PROGRAM FOR CALCULATING INTERPLANAR SPACINGS}

\author{
A. L. Coffey, Jr
}

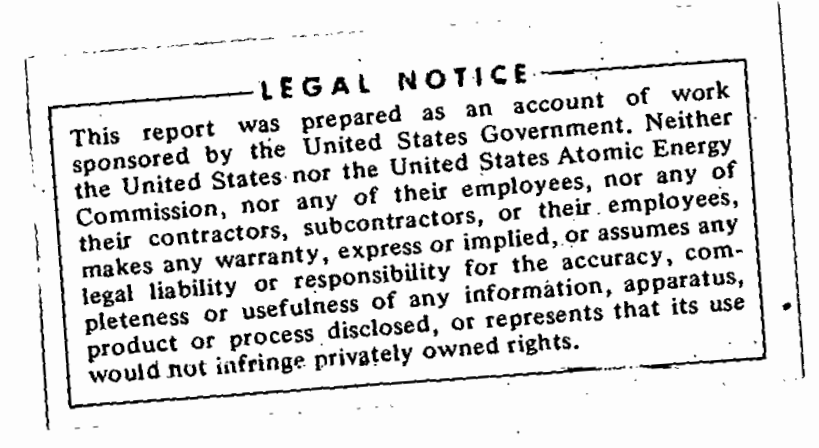

Oak Ridge, Tennessee 
Document $Y-1729$

TID-4500

DISTRIBUTION

Atomic Energy Commission

Keller, C. A.

Zachary, D. S., Jr

Oak Ridge Gaseous Diffusion Plant

Jordan, R. G.

Wilcox, W. J.; Jr

Oak Ridge Y-12 Plant

Ballenger, H.F. (2)

Baucum, W. E., Jr

Beeson, H. C.

Bell, B. B.

Bernander; N. K.

Briscoe, O.W.

Burkhart, L. E.

Carpenter, D. A.

Coffey, A. L., Jr

Ellingson, R. D.

Evans, G. W.

Ferguson, J. E.

Foulk, D. L.

Haeusler, K. R.

Hemphill, L. F.
Jackson, V. C.

Jamison, R. L.

Johnson, D. H.

Jones, F.W.

Kahl, K. G.

Keith, Alvin

Kite, H. .T.

McLendon, J. D.

Mitchel, G.W.

Oliphant, G. W.

Phillips, L. R.

Sears, D. R.

Smith, R. D.

Stoner, H. H.

Trotter, T.C.

Waters, J. L.

Wesley, R. L.

Yaggi, W. J.

$Y-12$ Central Files (5)

$Y-12$ Central Files (route)

$Y-12$ Central Files ( $Y-12 R C$ )

Paducah Gaseous Diffusion Plant

Winkel, R. A.

In addition, this report is distributed in accordance with the category Mathematics and Computers, as given in the "USAEC Standard Distribution Lists for Unclassified Scientific and Technical Reports", TID-4500. 


\section{ABSTRACT}

A time-share FORTRAN computer program has been developed which reliably calculates values of interplanar spacings $d, \sin ^{2} \theta, 2 \theta$, and the crystallographic planes, hkl, for materials whose unit cell parameters and extinction conditions are known. Calculated reflections that are systematically absent because of space group or translational symmetry are eliminated from the output list. 
CONTENTS

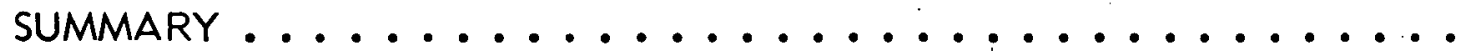

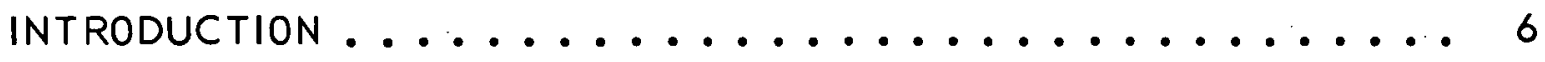

CALCULATING INTERPLANAR SPACINGS ............. 7

Program Description. ..................... 7

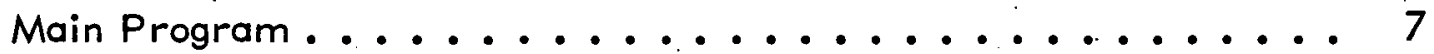

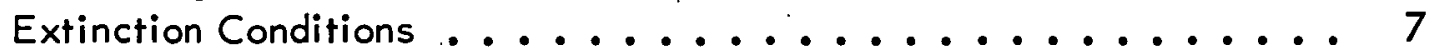

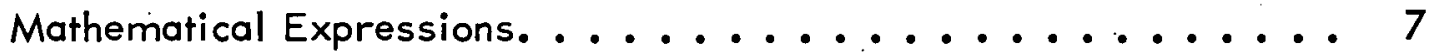

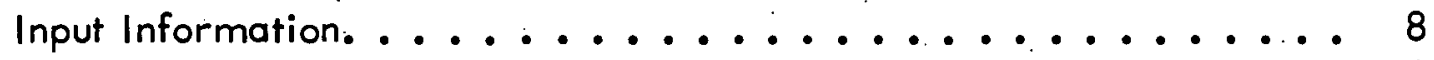

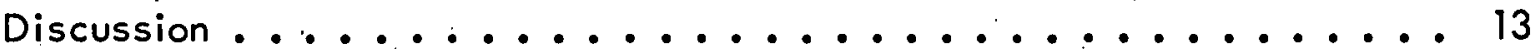

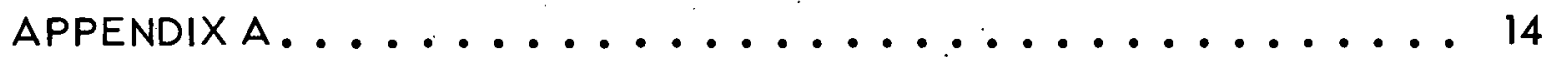

Source Program List. . . . . . . . . . . . . . . . 14

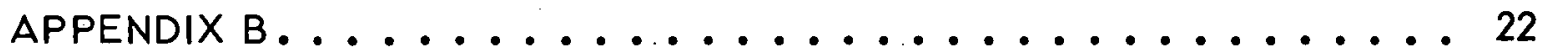

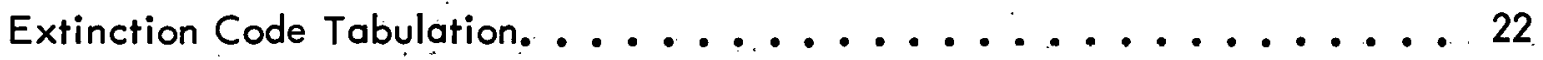

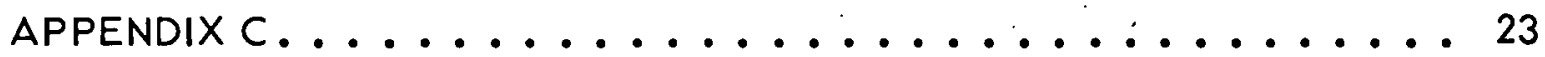

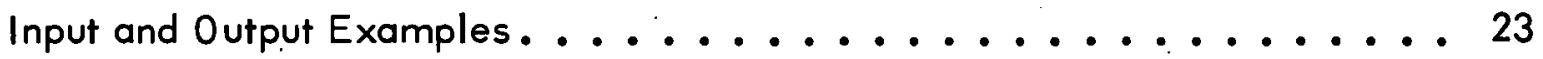

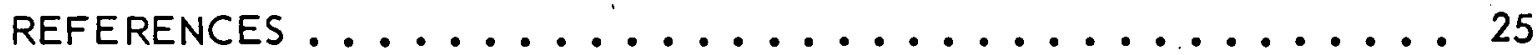


SUMMARY

For materials whose unit cell parameters and extinction conditions are known, interplanar spacings $d, \sin ^{2} \theta$, and $2 \theta$ values can be calculated for the crystallographic planes, hkl. Preexisting BASIC language programs for these calculations were found to be unsuitable for present needs; therefore, a fast, flexible, and easy-to-use FORTRAN program was developed. This program is a reliable revision of the one reported earlier. (1) Originally written for IBM 360 equipment, the program, now on a time-share system, contains a major modification in the extinction subroutine that systematically eliminates calculated reflections which are absent due to space group or translational symmetries.

The use of this FORTRAN program made a vast improvement in time requirements and in the integrity of results over the time-share programs previously available for these calculations. 


\section{INTRODUCTION}

Analysis of polycrystalline materials by $X$ rays and electron diffraction relies on the proper indexing of the diffraction pattern. Often this program requires information not found in the X-ray powder diffraction data file. For materials whose unit cell parameters and extinction conditions are known, however, identification is possible by matching the observed interplanar spacings of the unknown with values which may be calculated.

An available BASIC language computer program for the calculation of interplanar spacings, (2) although useful, was limited by the confusing practice of ordering the reflections on increasing hkl instead of on decreasing d values and by the lengthy operator time requirements. Modifications by this author, and subsequently by Sjodahl; et al, (3) rearranged the interplanar spacings in decreasing order and decreased operation time, respectively. However, the lack of any provision for supplying extinction information directly, and the necessity for combining two subprograms for the successful operation of the code were additional factors limiting the usefulness of this program.

In a search for a more suitable program, an X-ray powder diffraction trace simulation program, POWD2, (4) was considered. But, even when modified(5) to generate interplanar spacings only, the program was much too large for the available time-share systems.

A smaller FORTRAN IV program was then found in the literature; $(1)$ but, this program, though fast and reasonably flexible, listed d-spacings which should have been absent. However, a check of the program revealed that eliminating the error would probably be more time consuming than replacing the entire extinction routine with one that was previously determined to be reliable. An extra bonus resulting from the exchange of extinction subroutines was that the extinction data for this program and POWD2 would be identical. The substitution was accomplished, the input and output format revised, and the program performed as anticipated.

Since the program is written in FORTRAN, an option has been employed which allows the program to be saved and run in object code instead of source code. This option cuts drastically the time required for the program to run and for the information to be printed. The source program is listed in Appendix A. 


\section{CALCULATING INTERPLANAR SPACINGS}

\section{PROGRAM DESCRIPTION}

\section{Main Program}

Miller index generation within the main program is in the order of $h, k, l$. The sets $\pm(h k l)$ are generated by means of a three-level nested loop. As a set of hkl is generated, it is tested first for systematic extinction (subroutine EXTN), and then its corresponding dhkl is calculated and tested for containment within a sphere of reflection as determined by $2 \theta$ max.

For each allowed set (hkl), the program calculates $d_{h k l} \sin ^{2} \theta_{h k l}$, and $2 \theta_{h k l}$ which are then sorted on increasing $2 \theta_{\mathrm{hkl}}$ in blocks of 200 . If the input data permit the generation of more than 200 sets, the first 200 are sorted and tested, after which the program returns to the index generation routine and the process continues.

\section{Extinction Conditions}

Each of 230 three-dimensional space groups is. defined by a unique set of symmetry operations. These operations impose, on a single crystal, conditions affecting the appearance of various zones of $X$-ray reflections. The same conditions also pertain to polycrystalline diffractometry.

In the subroutine EXTN, the Miller indices are examined for the extinction conditions defined in the input data. Those reflections passing all the tests for nonextinction are accepted. Translational symmetry extinctions as well as lattice extinctions can be considered by the subroutine.

The subroutine tests a reflection by comparing the condition [ie, $(h+k) / 2 n]$ with its integral equivalent (ie, decimal portion truncated). If the two values are not the same, the reflection does not pass the test and is eliminated.

\section{Mathematical Expressions}

Interplanar spacings dhkl are calculated, as in the original program, $(1)$ using the expression:

$$
d_{h k l}=\left[v^{2} /\left(s_{11} h^{2}+s_{22} k^{2}+s_{33} l^{2}+2 s_{12} h k+2 s_{23} k l+2 s_{13} h l\right)\right]^{1 / 2},
$$

where: 


$$
\begin{aligned}
& v^{2}=a^{2} b^{2} c^{2}\left(1-\cos ^{2} \alpha-\cos ^{2} \beta-\cos ^{2} \gamma+2 \cos \alpha \cos \beta \cos \gamma\right), \\
& S_{11}=b^{2} c^{2} \sin ^{2} \alpha, \\
& S_{22}=a^{2} c^{2} \sin ^{2} \beta, \\
& S_{33}=a^{2} b^{2} \sin ^{2} \gamma, \\
& S_{12}=a b c^{2}(\cos \alpha \cos \beta-\cos \gamma), \\
& S_{23}=a^{2} b c(\cos \beta \cos \gamma-\cos \alpha), \text { and } \\
& S_{13}=a b^{2} c(\cos \alpha \cos \gamma-\cos \beta) \text {. }
\end{aligned}
$$

Values of $\sin \theta_{h k l}$ are computed from dhkl using Bragg's equation:

$$
\sin \theta_{h k l}=\frac{\lambda}{2 d_{h k l}} \text {. }
$$

The Hastings arcsine approximation is used to compute $2 \theta_{\mathrm{hkl}}$ values in the form:

$$
2 \theta_{h k l}=180.0-114.5916\left(\sqrt{1-\sin \theta_{h k l}}\right) \psi,
$$

where:

$$
\begin{aligned}
& \psi=1.570795207-0.214512362 \sin \theta_{h k l}+0.087876311 \sin ^{2} \theta_{h k l}-0.049958884 \\
& \sin ^{3} \theta_{h k l}+0.019349939 \sin ^{4} \theta_{h k l}-0.004337769 \sin ^{5} \theta_{h k l^{\circ}}
\end{aligned}
$$

Input Information

The input format required in the original program has been eliminated in favor of a free-field input to facilitate operation on a time-share system. The input must be placed in a data file named CRDATA in the following order:

Data 1. NJOB

Number of data sets to be processed. This information is needed only once. 
Data 2. TITLE

Any Hollerith character (30 spaces allowed) for identification.

Data 3. A Cell parameter a in angstroms

B Cell parameter $\underline{b}$ in angstroms

C Cell parameter $\mathrm{c}$ in angstroms

ALF Cell parameter $\underline{\alpha}$ in degrees

BET Cell parameter $\underline{\beta}$ in degrees

GAM Cell parameter $\underline{\gamma}$ in degrees

Data 4. TTMAX Maximum $2 \theta$ to be calculated in degrees

WAVE Wavelength of radiation used in angstroms

KSW1 External Program Control Indicator

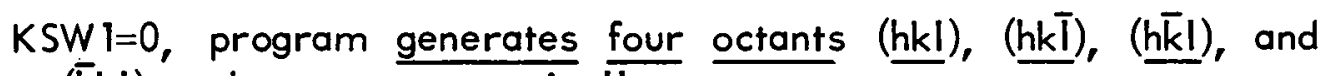
( $\overline{\mathrm{h}} k \mathrm{l})$, and outputs automatically

$K S W l=1$, program generates all positive (hkl) only, then looks for INDIC controls for further instructions

NOTE: With this option in effect, $K S W 1=1$, the program will not list output unless it is instructed to do so with an INDIC $=4$ control data.

\section{KSW2-Output Control Character}

KSW2=0, output routine lists onl; nonredundant crystallographic planes plus one representative of any redundant set. For example, in the cubic system, (200), (020), and (002) are redundant, and only one of these three would be listed.

$K S W 2=1$, output routine lists all planes that have passed extinction and limitation tests. 
Data 5. $\operatorname{IXXX}(14)$ or $11,12,13, \ldots 114$

\section{SPACE GROUP EXTINCTION CODES}

11. Nonextinction indicator for lattice type as follows:

$1 \mathrm{l}=1 \quad$ A-centered $(k+1=2 n)$

$\mid 1=2$ B-centered $(h+1=2 n)$

Il $=3$ C-centered $(h+k=2 n)$

Il=4 F-centered $(h+k=2 n, h+l=2 n, k+l=2 n)$

Il $=5$ i-centered $(h+k+I=2 n)$

Il $=6$ R-obverse $(-h+k+1=3 n)$

|1=7 R-reverse $(h-k+1=3 n)$

Il=8 Hexagonal $(h-k=3 n)$

Il=9 or 0 Primitive (no conditions).

12. Nonextinction indicator for (hk 0 ) zone as follows:

$12=0$ no conditions

$12=1$ a-glide $(h=2 n)$

$12=2$ b-glide $(k=2 n)$

$12=3$ n-glide $(h+k=2 n)$

$12=4 d$-glide $(h+k=4 n, h=2 n, k=2 n)$.

13. Nonextinction indicator for (hOl) zone as follows:

$13=0$ no conditions

$13=1$ a-glide $(h=2 n)$

$13=2$ c-glide $(=2 n)$

$13=3 n$-glide $(h+l=2 n)$

$13=4 d$-glide $(h+1=4 n, h=2 n, l=2 n)$.

14. Nonextinction indicator for ( $\mathrm{Okl})$ zone as follows:

14=0 no conditions

$14=1 \quad b$-glide $(k=2 n)$

14=2 c-glide $(1=2 n)$

$14=3$ n-glide $(k+1=2 n)$

$14=4 d$-glide $(k+l=4 n, k=2 n, l=2 n)$.

15. Nonextinction indicator for (hhl) zone as follows:

$15=0$ no conditions

$15=1 \quad c(n)$-glide $(1=2 n)$

$15=2 d$-glide $(2 h+l=4 n)$

$15=3 h+1=2 n$. 
16. Nonextinction indicator for (⿳亠丷⿵冂⿱十口) zone as follows:

$16=0$ no conditions

$16=1 \quad c(n)$-glide $(1=2 n)$

$16=2$ d-glide $(2 h+1=4 n)$.

17. Nonextinction indicator for (hkh) zone as follows:

$17=0$ no conditions

$17=1 \quad b(n)$-glide $(k=2 n)$

$17=2 \quad c$-glide $(2 h+k=4 n)$.

18. Nonextinction indicator for $(h k \bar{h})$ zone as follows:

$18=0$ no conditions

$18=1 \quad b(n)$-glide $(k=2 n)$

$18=2 d$-glide $(2 h+k=4 n)$.

19. Nonextinction indicator for (hkk) zone as follows:

$19=0$ no conditions

$19=1 \quad a(n)$-glide $(h=2 n)$

$19=2 \quad d$-glide $(2 k+h=4 n)$.

110. Nonextinction indicator for $(h k \bar{k})$ zone as follows:

$110=0$ no conditions

$110=1$ a $(n)$-glide $(h=2 n)$

$110-2$ d-glide $(2 k+h=4 n)$.

111. Nonextinction indicator for (h00) row as follows:

$111=0$ no conditions

$111=121$ or 42 screw $(h=2 n)$

$111=24$, or 43 screw $(h=4 n)$.

112. Nonextinction indicator for $(\mathrm{Ok} 0)$ row as follows:

$1 \mathrm{I}=U$ no conditions

$112=12$ or 42 screw $(k=2 n)$

$112=24$ or 43 screw $(k=4 n)$. 
113. Nonextinction indicator for (00I) row as follows:

$113=0$ no conditions

$113=121,42$, or 63 screw $(1=2 n)$

$113=231,32,62$, or 64 screw $(l=3 n)$

$113=3 \quad 4_{1}$ or $4_{3}$ screw $(I=4 n)$

$113=46_{1}$ or $6_{5}$ screw $(1=6 n)$.

114. EXTRA Nonextinction indicators for (hkl) as follows:

$114=0$ no conditions

$114=1 \quad h=2 n$

$114=2$. $\mid=2 n$

$114=3 h+k+1=4 n$

$114=4 \quad 2 h+1+4 n$

$114=5$ If $h-k=3 n$, then $l=2 n$

$114=6 h=4 n, k=4 n, 1=4 n$.

Data 6. INDIC external program control character. This option permits the user to control the course of the program if it is not desired to generate all four octants: For example, in an orthogonal crystal system, all of the lines on a powder diffractogram can be indexed using (hkl) all positive. The other three octants are redundant. In the monoclinic system, powder diffractograms may be indexed using (hkl) and $(\bar{h} \mathrm{kl})$. I he other two octants are redundant.

The INDIC control data are interrogated by the program only if $\mathrm{KSW}=1$. If this option is chosen, the course of the program is under the control of the user who must supply the proper sequence of INDIC data to obtain the desired output. The program generates (hkl) all positive and computes the associated values of $d, \sin ^{2} \theta$, and $2 \theta$ before interrogating the first INDIC control data.

INDIC $=1$, the program generates $(h k I)$ and computes the associated values of $d, \sin ^{2} \theta$, and $2 \theta$.

INDIC=2, the program generates ( $h \bar{k} \mid$ ) and computes the associated values of $d, \sin ^{2} \theta$, and $2 \theta$.

INDIC $=3$, the program generates $(\bar{h} \mathrm{kl})$ and computes the associated values of $d, \sin ^{2} \theta$, and $2 \theta$ :

INDIC $=4$, the program sorts and lists all the stored values of (hkl), $d, \sin ^{2} \theta$, and $2 \theta$, then tests $N J O B$ for additional computations. If NJOB is satisfied, the program terminates via a normal exit. 
The usual values of KSW.1, KSW2, and. INDIC are, respectively, 1, 0, and 4. For high-symmetry groups, where permutations of Miller indices are allowed, the conditions for each arrangement of indices must be defined separately if $K S W 2=1$; however, for $K S W 2=0$, the nonredundancy option will automatically eliminate permutable systems, such as 200,020 , or 002.

The lattice type for the material is chosen from the 11 list. Base-centered lattices will be given by $\mid 1=1,2$, or 3 ; face centered by $\mid 1=4$; body centered by $\mid 1=5$; rhombohedral or rhombohedral on hexagonal axes by $\mid 1=6$ or 7 , respectively; triply primative hexagonal by $1 \mathrm{l}=8$; and all simple or primative lattices by $11=9$ or 0 . Translational symmetry indicators $12-114$, may also be input data if available. Typical code indicators are listed in Appendix B.

\section{DISCUSSION}

For general use, the object code (CFOB) offers the most efficient operation. However, to list or to modify the program, the source code (CRSFCN) must be used. Changes in the program are automatically placed in object code upon operation of the source program. Size requirements of the object code are about 85 percent of that of the source code, and the time required for the example job to run in object code is about 20 percent of that required by the source version.

The printout of the lattice type and parameters, the extinction codes, and other relevant data are a check for the operator on the input data. The agreement between the calculated lines and the experimentally determined values is quite good, as can be seen in a typical example output and the corresponding ASTM file card listed in Appendix C. 


\section{AP.PENDIX A}

\section{SOURCE PROGRAM LIST.}

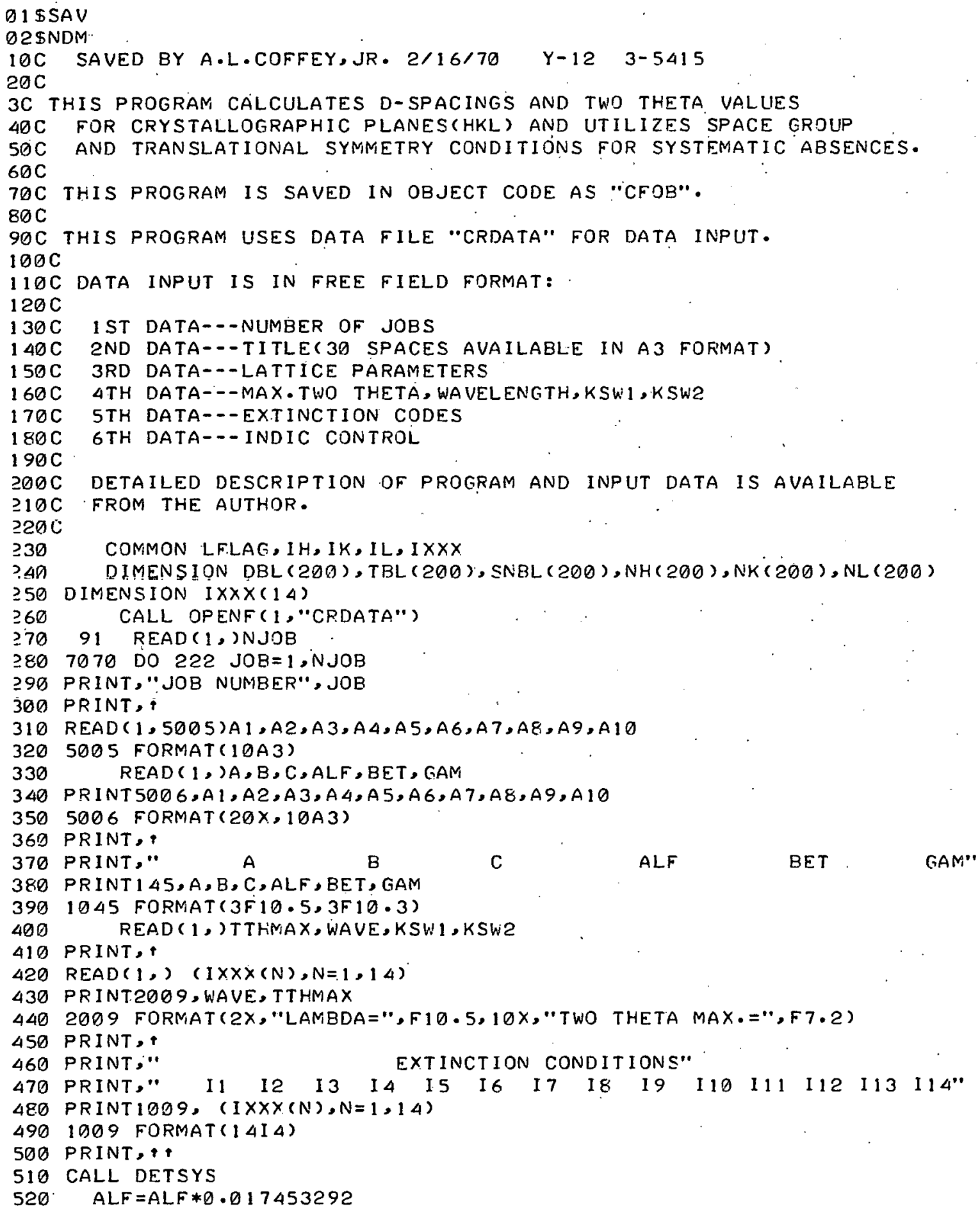




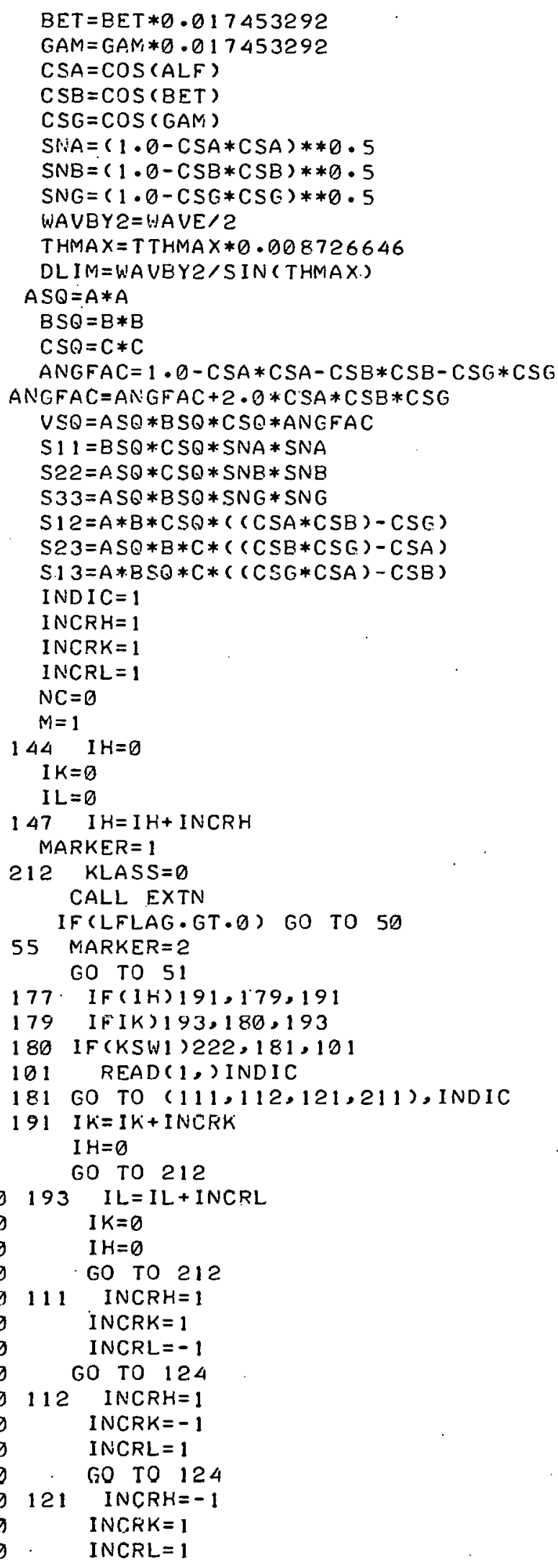




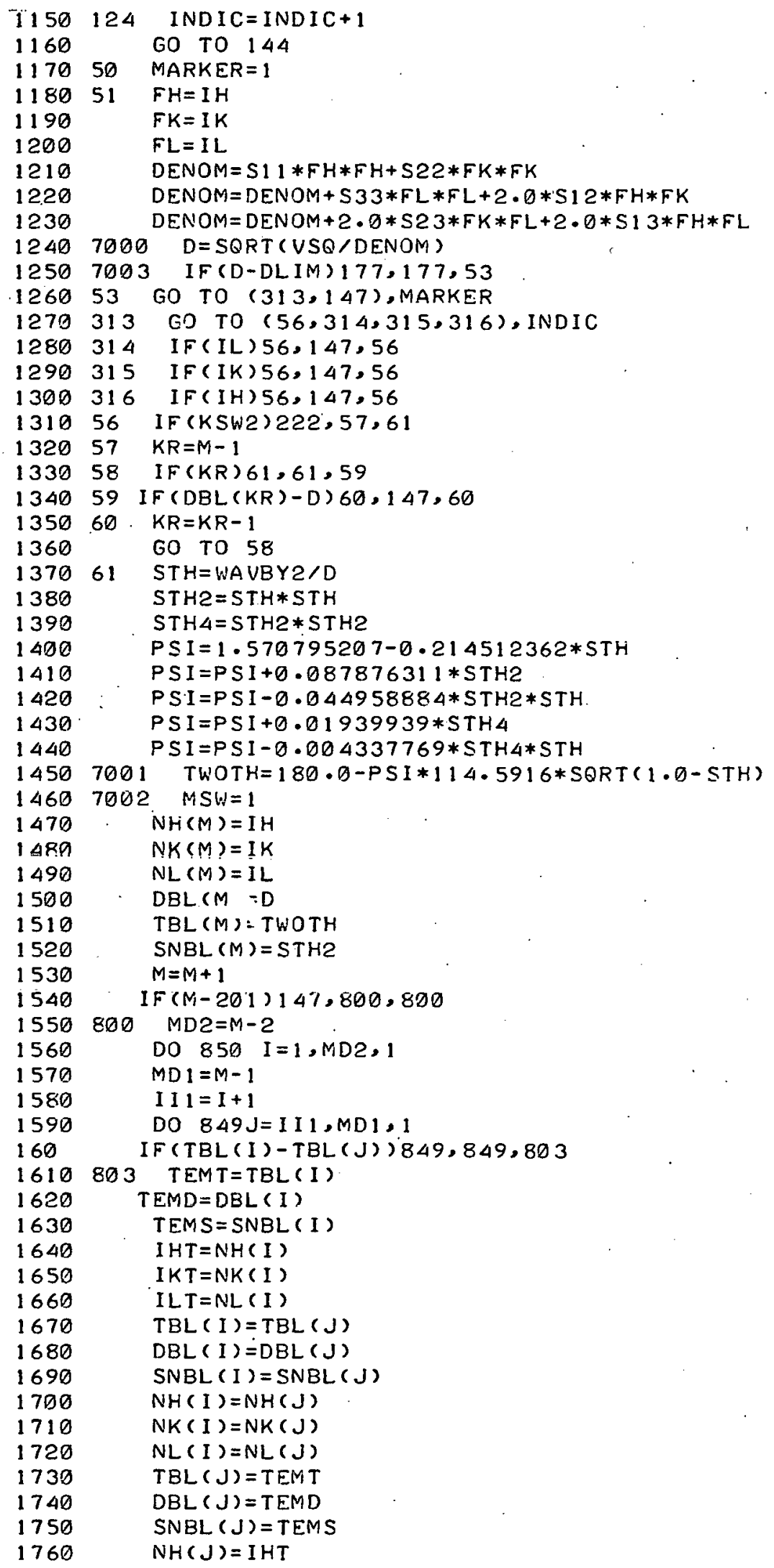




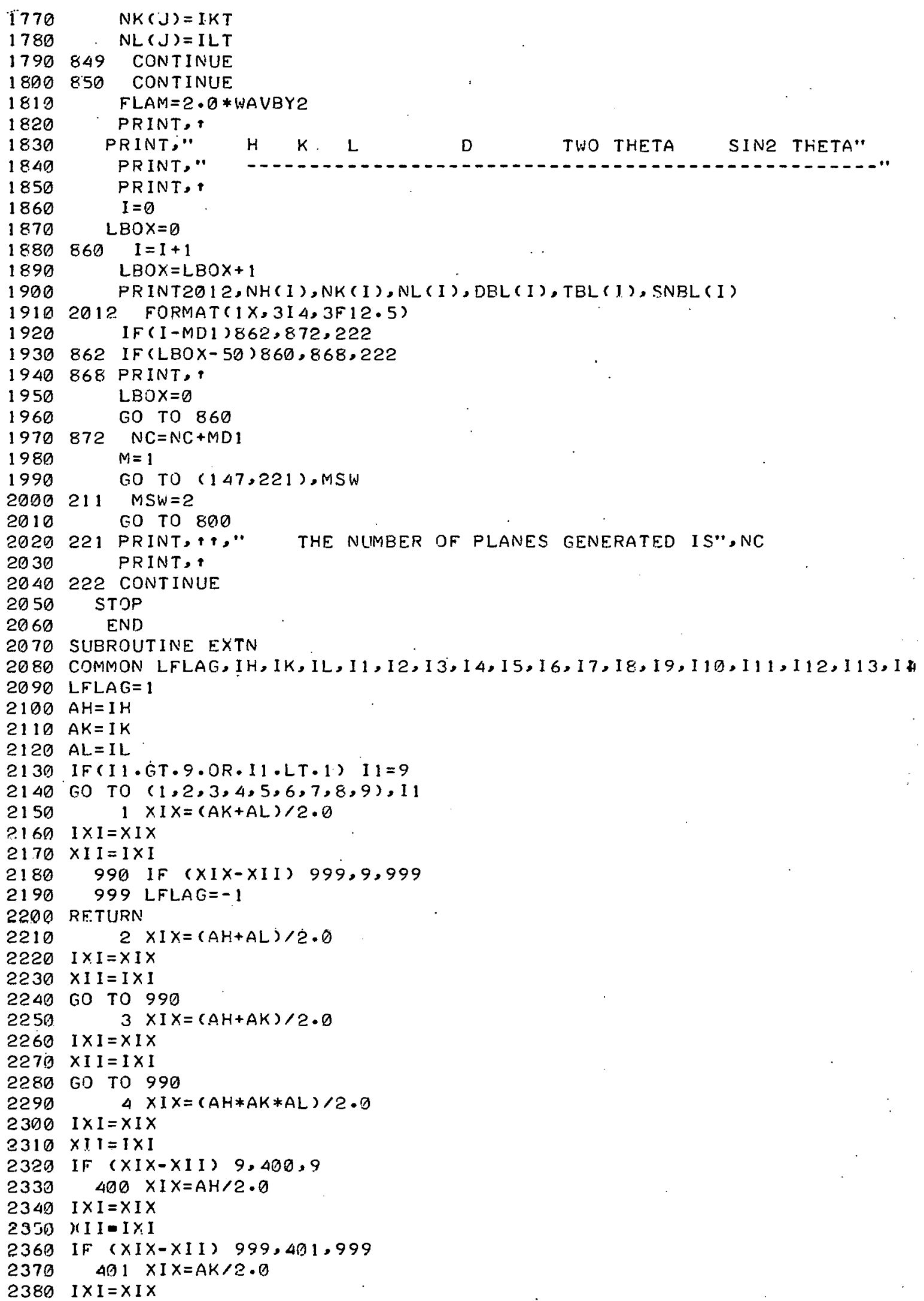




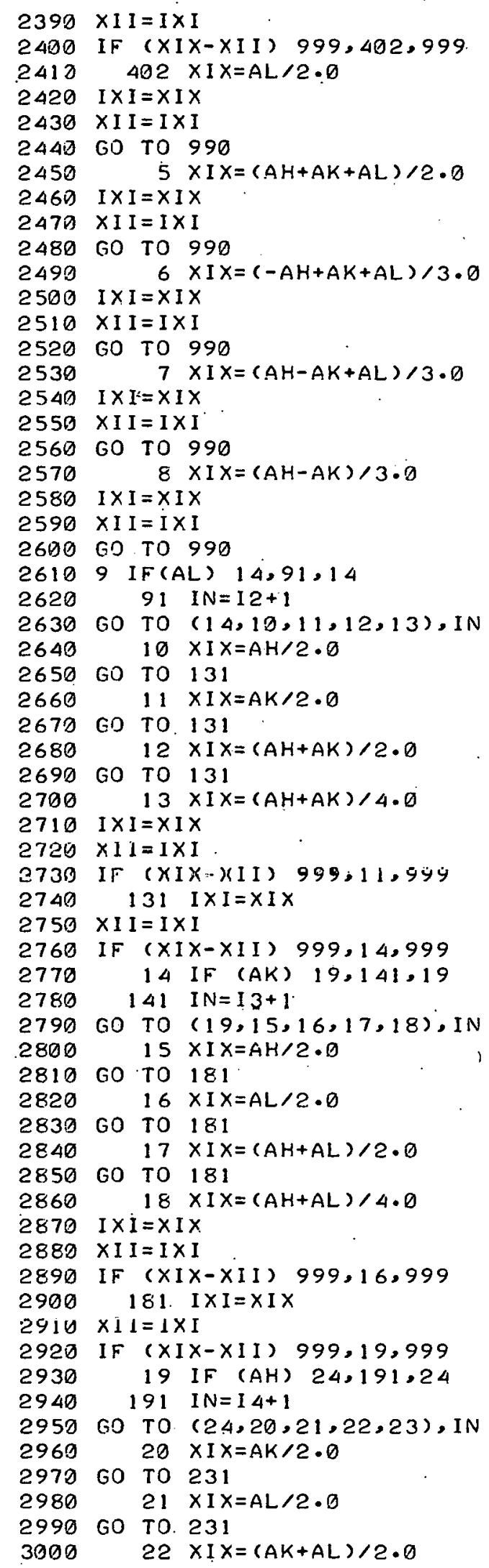




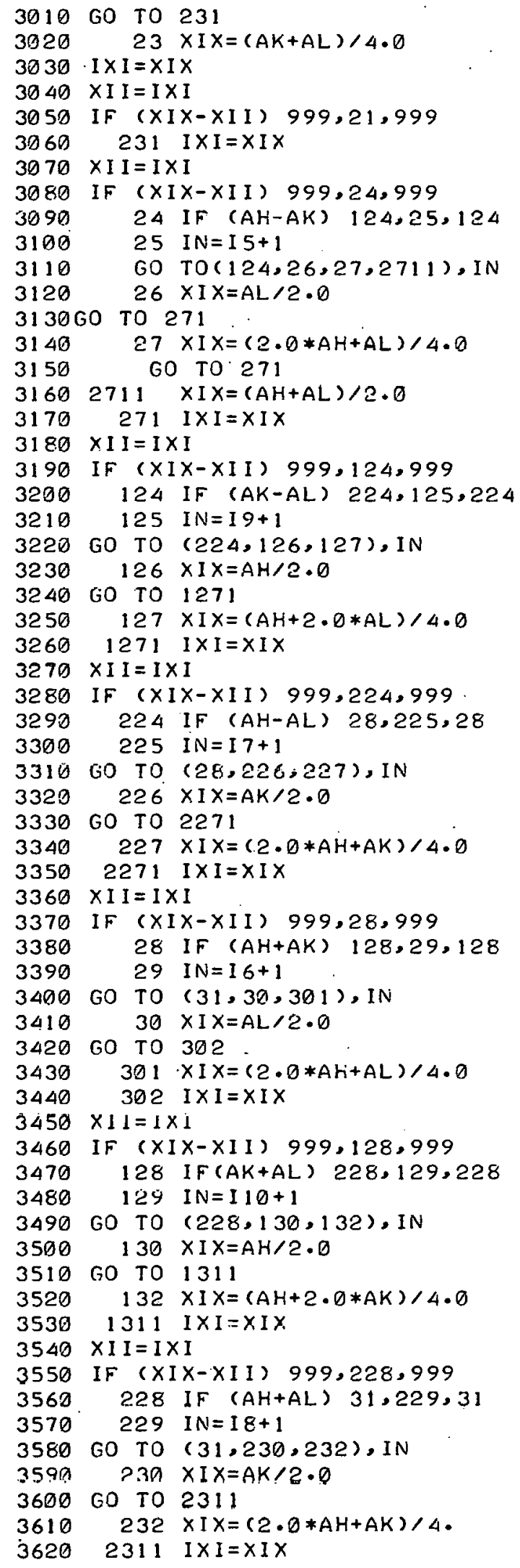




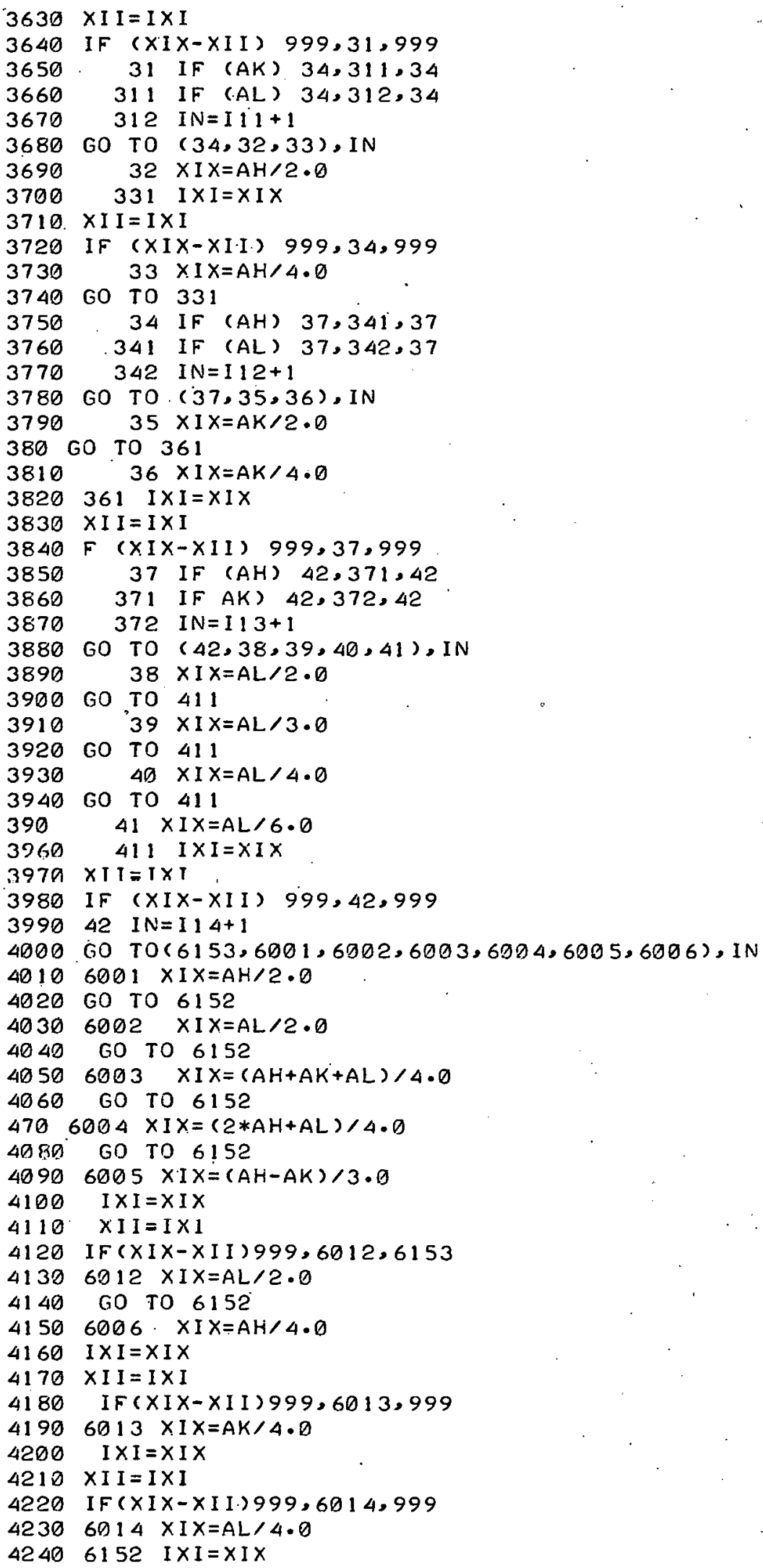




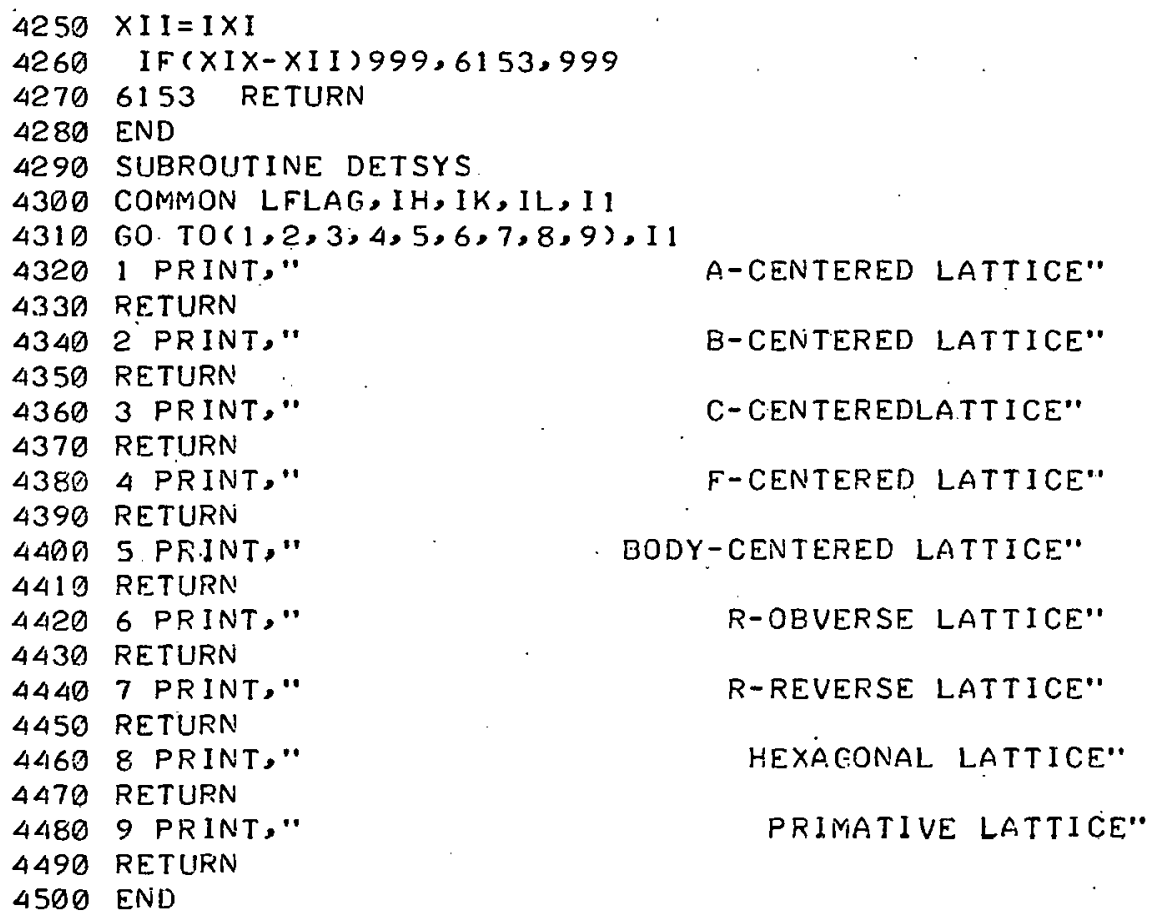




\section{APPENDIX B}

\section{EXTINCTION CODE TABULATION}

The appropriate extinction codes for a crystal structure can be obtained from the International Tables for $X$-ray Crystallography $(7)$ by knowing the space group, the number of equivalent positions, and the Wyckoff notation for the set of equivalent positions. Pearson(6) lists the necessary data for each structure according to Strukturbericht type. The extinction codes for some of the more common Strukturbericht types are as follows:

\begin{tabular}{|c|c|c|c|c|c|c|c|c|c|c|c|c|c|c|c|}
\hline \multirow{2}{*}{$\begin{array}{l}\text { STRUKTURBERICHT } \\
\text { TYPE } \\
\end{array}$} & \multirow{2}{*}{$\begin{array}{c}\text { SPACE GROUP } \\
\text { NUMBER }\end{array}$} & \multicolumn{14}{|c|}{ EXTINCTION CODES } \\
\hline & & $\overline{11}$ & 12 & 13 & 14 & 15 & 16 & 17 & 18 & 19 & 110 & 111 & 112 & 113 & 114 \\
\hline Al & 225 & 4 & 0 & 0 & 4 & 3 & 0 & 0 & 0 & 0 & 0 & 0 & 0 & 0 & 0 \\
\hline A2 & 229 & 5 & 0 & 0 & 3 & 1 & 0 & 0 & 0 & 0 & 0 & 0 & 0 & 0 & 0 \\
\hline A3 & 194 & 9 & 0 & & & $i$ & & 0 & 0 & & & & & & 5 \\
\hline$A 12$ & 217 & 5 & 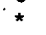 & & & & & & & & & & & & \\
\hline A.15 & 223 & 5 & & & & 1 & & & e: $A$ & $\|$ blo & iks she & uld be & zeros & but are & \\
\hline A20 & 63 & 3 & & 2 & & & & & ted & or ea & e of $r$ & ading. & & & \\
\hline BI & 225 & 4 & & & 4 & 3 & & & & & & & & & \\
\hline B2 & 221 & 9 & & & & & & & & & & & & & \\
\hline B3 & 216 & 4 & & & & 3 & & & & 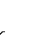 & & & & & \\
\hline B4 & 184 & 9 & & & & 1 & & & & & & & & & 5 \\
\hline $\mathrm{BB}_{1}$ & 194 & 9 & & & & $i$ & & & & & & & & & 2 \\
\hline $\mathrm{B}_{2}$ & 194 & 9 & & & & 1 & & & & & & & & & 5 \\
\hline B20 & 198 & 9 & & & & & & & & & & 1 & & & \\
\hline B27 & 62 & 9 & 1 & & 3 & & & & & & & & & & \\
\hline B31 & 62 & $y$ & $i$ & $\cdot$ & 3 & & & & & & & & . & & \\
\hline B32 & 227 & 4 & & & 3 & & & & & & & & & & \\
\hline $\mathrm{Cl}$ & 225 & 4 & & & 4 & 3 & & & & 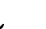 & & & & & 1 \\
\hline$=I_{0}$ & 216 & 4 & & & & 0 & & & & & & & & & \\
\hline $\mathrm{C} 2$ & 205 & 4 & 1 & 2 & 1 & & & & & & & & & & \\
\hline $\mathrm{C} 4$ & 136 & 5 & & & 3 & & & & & & & & & & \\
\hline C6 & 164 & 9 & & & & & & & & & & & & & \\
\hline $\mathrm{Cll}_{\mathrm{a}}$ & 139 & 5 & 3 & & 3 & 1 & & • & & & & . & & & \\
\hline $\mathrm{Cl}^{\circ}$ & 194 & 9 & & & & 1 & & & & & & & & & 2 \\
\hline $\mathrm{C} 15$ & 227 & 4 & & & 4 & 3 & & & & & & & & & 6 \\
\hline $\mathrm{Cl}$ & 140 & 5 & 3 & & 2 & 1 & & & & & & & & & 2 \\
\hline $\mathrm{C} 18$ & 58 & 5 & & 3 & 3 & & & & & & & & & & \\
\hline C32 & 191 & 9 & & & & & & & & & & & & & \\
\hline C36 & 194 & 9 & & & & 1 & & & & & & & & & 2 \\
\hline C 38 & 129 & 3 & 5 & & & & & & & & & & & & \\
\hline$c_{c}$ & 141 & 5 & 1 & & & 2 & & & & & & & & & 3 \\
\hline $\mathrm{DO}_{3}$ & 225 & 4 & & & 4 & 3 & & & & & & & & & 1 \\
\hline DO 18 & 194 & 9 & & & & 1 & & & & & & & & & 2 \\
\hline $\mathrm{DO}_{19}^{\circ}$ & 194 & 9 & & & & 1 & & & & & & & & & 5 \\
\hline $\mathrm{D} 2{ }_{1}$ & 221 & 9 & & & & & & & & & & & & & 2 \\
\hline D2 3 & 226 & 4 & & & 1 & 1 & & & & & & & & & 1 \\
\hline $02 \mathrm{~d}$ & 191 & 9 & & & & & & & & & & & & & \\
\hline D5 & 167 & 5 & & & & 1 & & & & & & & & & \\
\hline $\mathrm{D}_{2}$ & 164 & 9 & & & & & & . & & & & & & & \\
\hline $\mathrm{D}_{3}$ & 206 & 5 & & & 1 & & & & & & & & & & 1 \\
\hline$D 5_{8}$ & 62 & 9 & 1 & & 3 & & & & & & & & & & \\
\hline $05_{13}^{\circ}$ & 164 & 9 & & & & & & & & & & & & & \\
\hline $\mathrm{D}_{3}$ & 220 & 5 & & & & 2 & & & & & & & & & 6 \\
\hline $\mathrm{D} 7_{\mathrm{b}}^{\mathrm{s}}$ & 71 & 5 & & & & & & & & & & & & & \\
\hline$D 8_{1-3}^{\circ}$ & 229 & 5 & & & 3 & 1 & & & & & & & & & \\
\hline D8 8 & 193 & 9 & & & & & 1 & & & & & & & & 2 \\
\hline D8 & 136 & 5 & & & 3 & & & & & & & & & & \\
\hline D8 & 140 & 5 & 3 & & 2 & 1 & & & & & & & & & 2 \\
\hline $\mathrm{El}_{j}^{\mathrm{m}}$ & 122 & 5 & & & & 2 & & & & & & & & & \\
\hline E3 & 82 & 5 & & & & & & & & & & & & & \\
\hline $\mathrm{Ll}_{0}$ & 123 & 3 & & & & & & & & & & & & & \\
\hline $\mathrm{Ll}_{2}$ & 221 & 9 & & & & & & & & & & & & & \\
\hline$L_{2}^{2}$ & 225 & 4 & & & & & & & & & & & & & 1 \\
\hline $\mathrm{L}_{3}^{\prime}$ & 194 & 9 & & & & 1 & & & & & & & & & 2 \\
\hline
\end{tabular}




\section{APPENDIX C}

INPUT AND OUTPUT EXAMPLES

An example of the data in CRDATA is:

$$
\begin{array}{llc}
10 & 1 & \text { COPPER } \\
20 & \\
30 & 3.615,3 \cdot 615,3 \cdot 615,90,90,90 \\
40 & 165,1 \cdot 54178,1,0 \\
50 & 4 & \\
60 & 4 &
\end{array}
$$

\begin{tabular}{|c|c|c|c|c|c|c|c|c|c|c|c|}
\hline & & & & & & & & & & & \\
\hline+ - ons & 0.0 & 2000 & 2020 & מט & 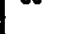 & & & & & & \\
\hline$\underset{1-\infty}{4}$ & 100 & 46 & 20 & 10 & C.000 & & & & & (n) & \\
\hline & & & & & & $d x$ & $\overline{1}$ & by & $d A$ & $\sqrt{4}$ & \$y \\
\hline $\begin{array}{l}\text { Din } \\
\text { und }\end{array}$ & $\begin{array}{c}\mathrm{ANON}_{1} \\
\text { C. D D }\end{array}$ & $\begin{array}{l}\text { Cut as } \\
\text { Aetrove } \\
\text { TATGE }\end{array}$ & & Poote, & & $\begin{array}{l}2.088 \\
1.8008 \\
1.278 \\
1.0900\end{array}$ & $\begin{array}{r}100 \\
46 \\
20 \\
17\end{array}$ & $\begin{array}{l}111 \\
200 \\
220 \\
311\end{array}$ & & & \\
\hline 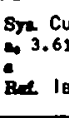 & & is & 80 & - Fus & & $\begin{array}{l}1.0436 \\
0.9038 \\
.8293 \\
.8093\end{array}$ & $\begin{array}{l}5 \\
3 \\
8 \\
8\end{array}$ & $\begin{array}{l}222 \\
400 \\
331 \\
420\end{array}$ & & & \\
\hline 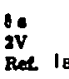 & $D_{10}{ }^{8}$ & $\begin{array}{l}\operatorname{nomp}_{\operatorname{mop}} \\
\cos ^{\prime}\end{array}$ & Collor & 8400 & & & & & & & \\
\hline $\begin{array}{l}\text { JoHNSO } \\
70000 \\
A_{T} 26^{\circ} \\
T_{0} \text { Nef } \\
3-1018\end{array}$ & $\begin{array}{l}\text { N AND } \\
\text { in vaC } \\
\text { Lace } 1\end{array}$ & THEY & BAMP & $\begin{array}{l}\text { ANNEALE } \\
\text { 3-1005, }\end{array}$ & $\begin{array}{l}A T \\
-1015\end{array}$ & & & & & & \\
\hline
\end{tabular}

NOTE: If the data are for a run of the source code (CRSFCN), all zeros must be included in the extinction code data.

The ASTM powder diffraction card for copper is:

The output from CFOB for the data just given is: 


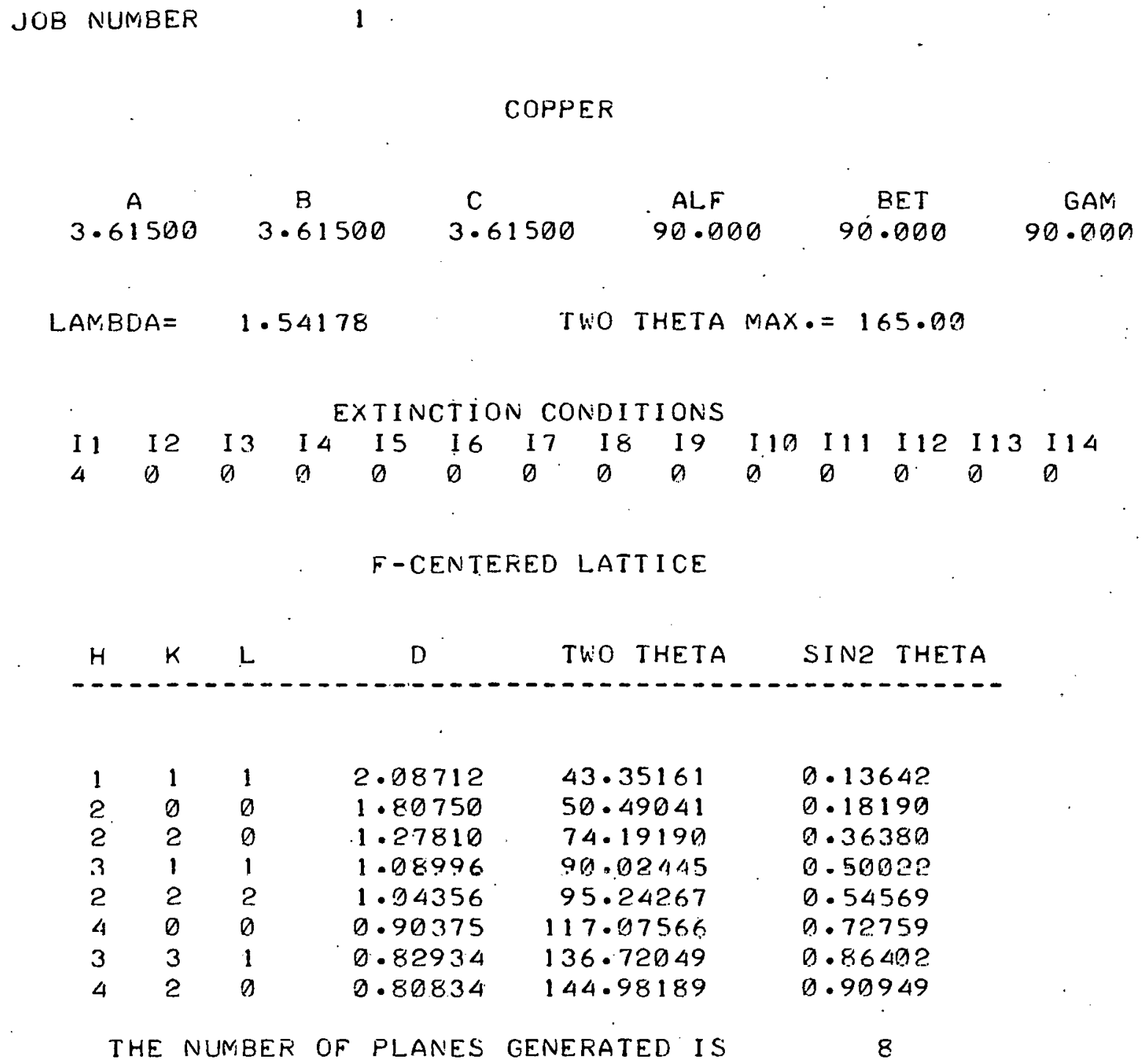




\section{REFERENCES}

(1) Werkema, G. Jo; A Revised FORTRAN IV Program to Calculate Crystallographic Functions, RFP-1329; The Dow Chemical Company, Rocky Flats Division, Golden, Colorado; May 14, 1969.

(2) Budelov, P. R. and Cullipher, J. R.; A Basic Language Computer Program for Calculating Interplanar Spacings, Y-1603; Union Carbide CorporationNuclear Division, Oak Ridge Y-12 Plant, Oak Ridge, Tennessee, February 15, 1968.

(3) Bartram, S. F., Rau, R. C., and Sjodahl, L. J.; DSPACE, A Program to Calculate Interplanar Spacings from Lattice Parameters, GEMP-680; General Electric, Missile and Space Division, Nuclear Systems Programs, Cincinnati, Ohio; March 11, 1969.

(4) Smith, D. K.; A Revised Program for Calculating X-Ray Powder Diffraction Patterns, UCRL-50264; Lawrence Radiation Laboratory, University of California, Livermore, California; June 12, 1967.

(5) Hermann, 0. W.; MILIN - A FORTRAN Computer Program for Generating Interplanar Spacings, Unpublished; Union Carbide Corporation-Nuclear Division, Oak Ridge Gaseous Diffusion Plant, Oak Ridge, Tennessee.

(6) Pearson, W. B.; Handbook of Lattice Spacings and Structures of Metals, $\underline{=}$ (1958); $\underline{\underline{2}}$ (1967); Pergamon Press, London, England.

(7) The International Union of Crystallography; International Tables for X-Ray Crystallography, 1, N. F. M. Henry and K. Lunsdale, Editors; the Kynoch Press, Birmingham, England (1965). 